\title{
A Study of Vitamin D Levels in HIV Seropositive Patients
}

\author{
Chandrashekar K. ${ }^{1}$, Vinod Gowda K.H. ${ }^{2}$, Chetan K. Ganteppanavar ${ }^{3}$, Veeresh B. Hubballi ${ }^{4}$, Ishwar S. Hasabi ${ }^{5}$ \\ 1, 2,3, 4, 5 Department of General Medicine, Karnataka Institute of Medical Sciences, Hubballi, Karnataka, India.
}

\section{ABSTRACT}

\section{BACKGROUND}

Vitamin D has an extensive role in immune function and regulation. Cardiovascular disease, Insulin resistance, cell-mediated immunity, autoimmune disease, infections like tuberculosis Vitamin D has a significant role. In autophagy, active form of vitamin D is found to have a role. Low vitamin D levels among HIV infected patients are associated with an increase in mortality, morbidity with a positive correlation between vitamin D levels and CD4 T cells. We wanted to study vitamin D levels in HIV patients, the correlation between CD4 counts and vitamin D levels, the correlation between vitamin D levels and opportunistic infections and also severity of the disease in HIV patients.

\section{METHODS}

A total of 104 confirmed HIV positive patients in KIMS, Hubballi fulfilling inclusion and exclusion criteria were included in the study. Detailed history, examination and lab studies were conducted.

\section{RESULTS}

Among the 104 HIV positive patients, 54 were male and 50 were female patients. 94 (90.4\%) patients had hypovitaminosis $\mathrm{D}(<30 \mathrm{ng} / \mathrm{ml})$ and $10(9.6 \%)$ patients had normal vitamin D levels (> $30 \mathrm{ng} / \mathrm{ml}$ ). Low vitamin D levels were associated with low CD4 counts with a positive correlation and Pearson correlation value of $(+0.87)$. Low vitamin D levels were associated with severe HIV disease (WHO stage 3 and 4) and with opportunistic infections like TB and oral candidiasis. All these above correlations were found to be statistically significant $(\mathrm{P}<0.001)$.

\section{CONCLUSIONS}

Vitamin D deficiency is frequently observed in HIV positive patients. Low vitamin D levels are associated with low CD4 counts, more severe disease and opportunistic infections. These suggest the importance of vitamin D in HIV positive patients in slowing disease progression and ultimately improving the quality of life and hence its levels need to be checked regularly.

\section{KEY WORDS}

HIV; TB; CD4 Counts; Vitamin D
Corresponding Author: Dr. Veeresh B. Hubballi, Senior Resident, Department of General Medicine, KIMS, Hubballi-580022, Karnataka, India.

E-mail: veerhubballi799191@gmail.com

DOI: $10.14260 /$ jemds/2022/13

How to Cite This Article:

Chandrashekar K, Gowda VKH Ganteppanavar CK, et al. A study of vitamin $D$ levels in HIV seropositive patients. J Evolution Med Dent Sci 2022;11(01):66-71, DOI: 10.14260/jemds/2022/13

Submission 10-12-2021,

Peer Review 20-12-2021,

Acceptance 12-01-2022,

Published 25-01-2022.

Copyright (C) 2022 Chandrashekar K. et al. This is an open access article distributed under Creative Commons Attribution License [Attribution 4.0 International (CC $B Y 4.0)]$ 


\section{BACKGROUND}

HIV is a retroviral disease known for causing a progressive decline in immune function. Counteracting interventions have a pivotal role in slowing the natural course of the disease, and also improving the quality of life. The latter is very vital in the face of HIV infection becoming a chronic disease in those patients with access to antiretroviral therapy. With its extensive involvement in the human immune response, vitamin D represents one such intervention. With improved quality of life as the disease has a chronic course and is best achieved with HAART (highly active antiretroviral therapy). Vitamin D as we know has an extensive role in the immune function and regulation of the body playing an important role in health and disease. ${ }^{1}$

The first case of HIV in India was recognized in Chennai in 1987 by Dr Jacob John and Dr Sunithi Solomon in commercial sex workers in Chennai. The government of India launched the free ART programme on $1^{\text {st }}$ April 2004, starting with eight tertiary-level government hospitals in the six high-prevalence states of Andhra Pradesh, Karnataka, Maharashtra, Tamil Nadu, Manipur, and Nagaland.

Vitamin D levels among rural populations were higher compared to the urban population. Studies have demonstrated hypovitaminosis $\mathrm{D}$ to be more common in urban subjects compared to rural subjects. In some studies, hypovitaminosis was equally prevalent among urban and rural subjects.

Vitamin D has a significant role in cardiovascular disease, insulin resistance, cell-mediated immunity, autoimmune disease, depression, and in control of infections such as tuberculosis.2,3,4 In processes like autophagy occurring intracellularly, the active form of vitamin $D$ is found to have a role. Autophagy plays an important role in the control of many intracellular microorganisms and maintains cellular homeostasis during conditions of stress. ${ }^{5}$
Studies have demonstrated inhibition of HIV-1 viral replication in human macrophages which are incubated with $1,25(\mathrm{OH}) 2 \mathrm{D}$, a process that was partially mediated by autophagy. ${ }^{6}$ Similar results were also seen for Mycobacterium tuberculosis (Mtb) infected cells and cells which were coinfected with HIV-1 and Mycobacterium Tuberculosis. ${ }^{7}$

T-cell activation and the genes involved in cell proliferation and differentiation are suppressed by vitamin D. Cathelicidin, helps in the mycobacterial killing. The active form of vitamin D 1, 25- $(\mathrm{OH}) 2 \mathrm{D}$ enhances the production of IL-37, a class of defensins-antimicrobial peptides of the cathelicidin family, resulting in TB destruction. Since vitamin D has anti-inflammatory and antimicrobial action, its deficiency plays an important role in the immune reconstitution inflammatory syndrome (IRIS). Combination of HIV infection and insufficient local production of $1,25(\mathrm{OH})$ 2D could together promote cytokine generation and its action resulting in tissue dysfunction.

At present, serum concentration of 25-hydroxyvitamin D $[25(\mathrm{OH}) \mathrm{D}]$ is considered to be the best indicator of vitamin $\mathrm{D}$ status as it represents cumulative exposure to sunlight and dietary intake of vitamin D. ${ }^{8}$ HIV infected patients have decreased vitamin D levels. Decreased levels are attributed to increased levels of TNF- $\alpha$ or other inflammatory mediators, decreased conversion of 25(OH)D to $1,25(\mathrm{OH}) 2$ D via $1-\alpha$ hydroxylase, effects of antiretroviral therapy (ART), both the protease inhibitor (PI) and non-nucleoside reverse transcriptase inhibitor (NNRTI) classes of antiretroviral agents enhance vitamin $\mathrm{D}$ metabolism via modulation of the cytochrome P450 system and vitamin D hydroxylation and possibly increase utilization.9-12 Studies have shown low vitamin D levels among HIV infected patients, and also associated increase in mortality and morbidity and a positive correlation between vitamin D levels and CD4 T cells. ${ }^{13-15}$

\begin{tabular}{|c|c|c|c|}
\hline \multicolumn{4}{|c|}{ WHO Clinical Staging of HIV } \\
\hline Stage - I & Stage - II & Stage - III & Stage - IV \\
\hline $\begin{array}{l}\text { 1. Asymptomatic } \\
\text { 2. Persistent generalized } \\
\text { lymphadenopathy }\end{array}$ & $\begin{array}{ll}\text { 1. } & \text { Moderate unexplained } \\
\text { 2. } & \text { Reight loss } \\
\text { infections (sinusitis, } \\
\text { tonsillitis, otitis media, and } \\
\text { pharyngitis) } \\
\text { 3. } \\
\text { 4. } \\
\text { 5erpes zoster } \\
\text { 5. } & \text { Recurrent oral ulceration } \\
\text { 6. } & \text { Papular pruritic eruptions } \\
\text { 7. } & \text { Seborrheic dermatitis } \\
\text { 8. } & \text { Fungal nail infections }\end{array}$ & $\begin{array}{l}\text { 1. Unexplained severe } \\
\text { weight loss, unexplained } \\
\text { chronic diarrhoea for }>1 \\
\text { month } \\
\text { 2. Unexplained persistent } \\
\text { fever for }>1 \text { month } \\
\text { 3. Pulmonary tuberculosis } \\
\text { (current) } \\
\text { 4. Persistent oral candidiasis } \\
\text { (thrush) } \\
\text { 5. Oral hairy leukoplakia } \\
\text { 6. Severe presumed bacterial } \\
\text { infections } \\
\text { 7. Unexplained anaemia } \\
\text { (haemoglobin }<8 \text { g/dL) } \\
\text { 8. Chronic thrombocytopenia } \\
\text { (platelets }<50,000 \\
\text { cells } / \mu \mathrm{L} \text { ) Neutropenia } \\
\text { (neutrophils }<500 \\
\text { cells } / \mu \mathrm{L} \text { ) }\end{array}$ & $\begin{array}{l}\text { 1. HIV wasting syndrome } \\
\text { 2. Pneumocystis pneumonia } \\
\text { 3. Recurrent severe bacterial } \\
\text { pneumonia } \\
\text { 4. Chronic HSV } \\
\text { 5. Oesophageal / Respiratory } \\
\text { candidiasis } \\
\text { 6. Extrapulmonary TB } \\
\text { 7. CMV infection } \\
\text { 8. CNS toxoplasmosis } \\
\text { 9. HIV encephalopathy } \\
\text { 10. Kaposi sarcoma } \\
\text { 11. Cryptococcosis, extrapulmonary } \\
\text { 12. Disseminated NTM infection } \\
\text { 13. PML } \\
\text { 14. Chronic } \\
\text { cryptosporidiosis/isosporiasis } \\
\text { 15. Disseminated mycosis } \\
\text { 16. Lymphoma } \\
\text { 17. Invasive cervical carcinoma } \\
\text { 18. Symptomatic HIV-associated } \\
\text { nephropathy/cardiomyopathy }\end{array}$ \\
\hline
\end{tabular}




\section{Objectives}

1. To study vitamin D levels in HIV positive patients.

2. To know the correlation between CD4 counts and vitamin D levels in patients with HIV.

3. To know the correlation between vitamin D levels and opportunistic infections and also severity of the disease in HIV patients.

\section{METHODS}

Confirmed HIV positive inpatients in the Department of Medicine and patients attending ART Centre in Karnataka Institute of Medical Sciences, Hubballi, from November 2015 to January 2017 were included. Permission was sought from Karnataka State AIDS Prevention Society, Bengaluru for conducting studies on HIV patients and the confidentiality of the details of the patients was maintained as per the NACO guidelines and protocols. WHO staging was applied to categorize the patients. Complete haemogram, blood urea, serum creatinine, HIV(serology), HBsAg status, electrocardiogram, chest X-ray, vitamin D levels $(25-\mathrm{OH}$ vitamin D levels) by fully automated chemi luminescentimmuno-assay, CD4 counts, ultrasonography of abdomen in selected cases, FNAC of lymph nodes in selected cases, other relevant investigations were obtained as and when required. The study categorized the CD4 count of $>500$ cells/cumm as normal and 499-200 cells/cumm as low and <199 cells/cumm as very low. Similarly, the vit D levels were categorized as $>30 \mathrm{ng} / \mathrm{dL}$ : Optimal/sufficient, $20-30 \mathrm{ng} / \mathrm{dL}$ : insufficient and $<20 \mathrm{ng} / \mathrm{dL}$ : deficient and $<10 \mathrm{ng} / \mathrm{dL}$ as very low levels. The normal TLC level of 4000-11000 cells/cumm was unaltered in our study. The study also observed the associated opportunistic infections mainly tuberculosis, cryptococcosis, pneumocystis, herpes, hepatitis and candidiasis. However, other opportunistic infections as per WHO staging if present were also taken into consideration.

Participants were selected based on inclusion and exclusion criteria and informed and written consent was obtained from them.

\section{Statistical Analysis}

It is a single centred, time-bound and cross-sectional type of study. The data were entered in Microsoft Excel and analysed using Epi Data analysis V2.2.2.186 and Stata 12 software. The continuous variables like age, vitamin D level, CD4 count, serum creatinine level, haemoglobin, duration of illness, MCV, total leukocyte count, height, weight and body mass index were expressed as mean (standard deviation) or median (Interquartile range) based on the distribution of data. The categorical variables like age category, gender, ART regimen, serodiscordant stage of the spouse, type of opportunistic TB infections, WHO staging of disease, vitamin D categories and other opportunistic infections were expressed in percentages. The association between age categories, gender, WHO staging, opportunistic infections (oral candidiasis, skin infections, TB), ART regimen, BMI categories, haemoglobin values and vitamin $D$ level were identified using unpaired $t$ test or Kruskal Wallis test or one way ANOVA or Mann Whitney $U$ test. The association between haemoglobin and gender was identified using an unpaired t-test. The association between CD4 counts and gender was expressed using Mann Whitney U test. The correlation of vitamin D level with CD4 count, serum creatinine level, haemoglobin, duration of illness, MCV, total leukocyte count was identified using Pearson correlation. The P-value of $<0.05$ was considered for statistical significance. The required sample size calculated using the previous study mean (SD) values of 22.5 (14.3) ng/ml was 101, with $5 \%$ of alpha error, a confidence level of $95 \%$ and relative precision of $20 \%$.

\section{Inclusion Criteria}

- Confirmed HIV positive patients - both inpatient and OPD cases.

- $\quad$ Patient on HAART therapy.

\section{Exclusion Criteria}

- $\quad$ Age less than 18 years.

- Already on vitamin D supplementation.

- Chronic kidney disease.

A detailed history was taken and examination was done as per the structured proforma for each patient. Ethical clearance for the study was obtained from the Ethical Committee of KIMS, Hubballi.

\section{RESULTS}

The present study had a majority of the population belonging to the age group of 31-40 years constituting $47 \%$ of the study followed by $41-50$ years (26\%). The age group of the study participants was divided into 18-20, 21-30, 31-40, 41-50, 5160 , and 61-70 years.

Out of the $104 \mathrm{HIV}$ patients, 54 (51.9\%) were males and 50 (48.1\%) were females. Among these 104 study populations, $33.7 \%$ of the spouses were affected.

An almost equal number of people with ZLN and TLE regimen were included in the study and people with ZLN and TLE had vitamin D levels of $16.4 \mathrm{ng} / \mathrm{ml}$ and $20.9 \mathrm{ng} / \mathrm{ml}$ respectively. The TLE regimen had better vitamin D levels compared to ZLN.

The mean duration of HIV among the study population was $5.3 \pm 3.1$ years. With respect to nutritional status, $63.5 \%$ had a normal BMI and $27.9 \%$ were underweight.

$90.4 \%$ of the population had hypovitaminosis of $<30$ $\mathrm{ng} / \mathrm{ml}$. Mean vitamin D levels in males and females were $22.49 \mathrm{ng} / \mathrm{ml}$ and $15.05 \mathrm{ng} / \mathrm{ml}$ respectively.

The mean haemoglobin of the study population was 10.1 $\pm 2.4 \mathrm{~g} / \mathrm{dL} .78 .8 \%$ had anaemia and $\mathrm{Hb} \%$ of $<12 \mathrm{~g} / \mathrm{dL}$. Mean vitamin D levels in a patient with $\mathrm{Hb}>12 \mathrm{~g} / \mathrm{dl}$ and $\mathrm{Hb}<6$ $\mathrm{g} / \mathrm{dL}$ were $30.04 \mathrm{ng} / \mathrm{ml}$ and $14.1 \mathrm{ng} / \mathrm{ml}$ respectively with a significant statistical correlation and P-value of $<0.001$. A significant statistical correlation was also seen with blood parameters like TLC and MCV with vitamin D levels and with a P-value of $<0.001$.

The mean CD4 count of the study population was $410.6 \pm$ 275.5 cells. The median (IQR) CD4 cell count in males and females was 389.5 cells and 230 cells respectively.

Patients with a CD4 count of $>500$ cells had vitamin D levels of $29.6 \mathrm{ng} / \mathrm{ml}$ which is near normal of $>=30 \mathrm{ng} / \mathrm{ml}$. 
With respect to the WHO staging of HIV, people with mean vitamin D level $>20 \mathrm{ng} / \mathrm{ml}$ were in stage I and II and with $<15$ $\mathrm{ng} / \mathrm{ml}$ were in stage III and IV. Patients without and with HIVTB coinfection had mean vitamin D levels of $21.9 \mathrm{ng} / \mathrm{ml}$ and $11.72 \mathrm{ng} / \mathrm{ml}$, patients without and with oral candidiasis had mean vitamin D levels of $19.55 \mathrm{ng} / \mathrm{ml}$ and $8.52 \mathrm{ng} / \mathrm{ml}$, patients without and with herpes labialis had mean vitamin $D$ levels of $19.16 \mathrm{ng} / \mathrm{ml}$ and $10.16 \mathrm{ng} / \mathrm{ml}$ respectively. A statistically insignificant negative correlation was seen with vitamin D and duration of illness with a P-value of 0.107. As the duration of HIV illness increased, the levels of vitamin D reduced with Pearson correlation coefficient $(r)=0.16$.

\begin{tabular}{|ccc|}
\hline WHO Staging & Number of Participants & Frequency \\
1 & 15 & 14.4 \\
2 & 44 & 42.3 \\
3 & 34 & 32.7 \\
4 & 11 & 10.6 \\
Total & 104 & 100 \\
ART Regimen & Number of Participants & Frequency \\
ZLN & 46 & 44.2 \\
TLE & 58 & 55.8 \\
Total & $\mathbf{1 0 4}$ & $\mathbf{1 0 0}$ \\
\hline Table 1. Table Showing the Distribution of Subjects with Different \\
Stages of HIV as Per WHO and Subjects with the Different HAART \\
\multicolumn{3}{|c}{} \\
\multicolumn{3}{|c}{} \\
\multicolumn{2}{|c}{} \\
\hline
\end{tabular}

Among the 104 HIV positive patients, 15 (14.4 \%) patients belonged to stage $1,44(42.3 \%)$ belonged to stage 2 , 34 (32.7\%) belonged to stage 3 and 11 (10.6\%) patients belonged to stage 4 of WHO staging of HIV. There were 31 (29.8\%) HIV positive patients with TB co-infection. Among these patients, 19 had pulmonary tuberculosis, 6 had TB lymphadenopathy, 4 had TB pleural effusion and 2 had TB meningitis.

Among the 104 HIV patients, 6 (5.8\%) patients were affected with oral candidiasis, 3 patients had orolabial herpes and two patients were HBsAg positive.

The majority of the participants were in stage II and stage III constituting $42.3 \%$ and $32.7 \%$ respectively. $55.8 \%$ were on the TLE regimen and $44.2 \%$ were on the ZLN regimen.

\begin{tabular}{|ccc|}
\hline Vitamin D Levels (NG/ML) & Number of Participants & Frequency \\
$<20.0$ & 60 & 57.7 \\
$20.0-29.9$ & 34 & 32.7 \\
$>=30.0$ & 10 & 9.6 \\
Mean (SD) & $18.9(9.5)$ & Range $: 4.2-57.9$ \\
CD4 Values & Number of Participants & Frequency \\
$<200$ & 22 & 21.1 \\
$200-500$ & 53 & 51 \\
$>500$ & 29 & 27.9 \\
Mean (SD) & $410.6(275.5)$ & Range $: 144-1216$ \\
\hline \multicolumn{3}{|c}{ Table 2. Table Showing the Subjects Distribution with Vitamin } \\
& D Levels and CD4 Counts \\
\hline
\end{tabular}

22 (21.2\%) patients had CD4 counts < 200, 53 (51\%) patients had CD4 counts between 200 and 500 and 29 (27.9 $\%$ ) patients had CD4 counts $>500$. Mean (SD) CD4 count was $410.6 \pm 275.5$. The median (IQR) values of CD4 counts in males and females were 389.5 (230-678) and 230 (186.75426) respectively. There was a statistically significant difference in CD4 counts between male and female study participants. $(\mathrm{P}=0.001)$.

In our study, out of $104 \mathrm{HIV}$ patients, 94 patients (90.4\%) had hypovitaminosis $(<30 \mathrm{ng} / \mathrm{ml})$ and $10(9.6 \%)$ patients had sufficient vitamin D levels $(\geq 30 \mathrm{ng} / \mathrm{ml}$ ). Among the 94 patients who had hypovitaminosis D, 60 patients were vitamin D insufficient $(<20.29 .9 \mathrm{ng} / \mathrm{ml})$ and 34 patients were vitamin D deficient (<20 ng/ml). Mean (SD) vitamin D level among the study participants was $18.9 \pm 9.5 \mathrm{ng} / \mathrm{ml}$.

\begin{tabular}{|cccc|}
\hline WHO Staging & Vitamin D - Mean & Standard Deviation & P Value * \\
\hline 1 & 23.6 & 11.05 & \\
2 & 21.61 & 9.74 & $<0.001 \S$ \\
3 & 14.91 & 7.67 & \\
4 & 14.11 & 4.49 & \\
\hline Table 3. Table Showing WHO Stage of the Patient with Serum \\
\multicolumn{4}{|c|}{ Vitamin D Levels } \\
\hline \# One way ANOVA and § significant P-value.
\end{tabular}

It can be seen that as the vitamin D levels decline, the severity of the disease increases. Statistically, a significant difference was observed in vitamin $\mathrm{D}$ level among the different WHO stages of HIV infection $(\mathrm{P}<0.001)$

\begin{tabular}{|cccc|}
\hline $\begin{array}{c}\text { CD4 } \\
\text { Counts }\end{array}$ & $\begin{array}{c}\text { Number of } \\
\text { Participants }\end{array}$ & $\begin{array}{c}\text { Mean (SD) Values } \\
\text { of Vitamin D }\end{array}$ & P Value \# \\
$<200$ & 22 & $8.6(3.4)$ & \\
$200-500$ & 53 & $17.3(4.7)$ & $<0.001$ \\
\hline 500 & 29 & $29.6(8.9)$ & \\
\hline \multicolumn{4}{|c|}{ Table 4. CD4 Cell Count Distribution among Participants and Their } \\
Mean Vitamin D Levels
\end{tabular}

It was observed that as the vitamin D level increases there was an increase in the CD4 counts with a significant statistical correlation with a P-value of $<0.001$.

The median (IQR) values of vitamin $D$ in age groups 20 $30,31-40,41-50,51-60$ and 60-70 years were 14.85 (11.02 18.9), 17.71 (10.66 - 25.66), 19.46 (12.7 - 23.32), 20.07 (12.31 - 23.18) and 14.59 (10.52 - 14.59) units /dl respectively. Though there was an increase in vitamin $D$ level as the age advanced, there was no significant difference in vitamin $\mathrm{D}$ level in terms of age $(\mathrm{P}=0.809)$. The mean (SD) level of vitamin D among males was $22.49(9.67) \mathrm{ng} / \mathrm{ml}$ and among females was 15.05 (7.81) $\mathrm{ng} / \mathrm{ml}$ with a statistically significant difference in vitamin $\mathrm{D}$ level between male and female study participants. $(\mathrm{P}<0.001)$.

\begin{tabular}{|cccc|}
\hline Type of ART & Vitamin D - Mean & Standard Deviation & P Value ${ }^{\#}$ \\
ZLN & 16.4 & 7.85 & $<0.016^{\S}$ \\
TLE & 20.9 & 10.34 & \\
\hline \multicolumn{4}{|c|}{ Table 5. The HAART Regimen and Vitamin D Levels in Serum } \\
\hline \# unpaired t-test and $\S$ significant P-value. \\
\hline
\end{tabular}

People on the TLE regimen had higher mean (SD) levels of vitamin $\mathrm{D}$ than those on the ZLE regimen with a significant statistical difference and P-value of 0.016

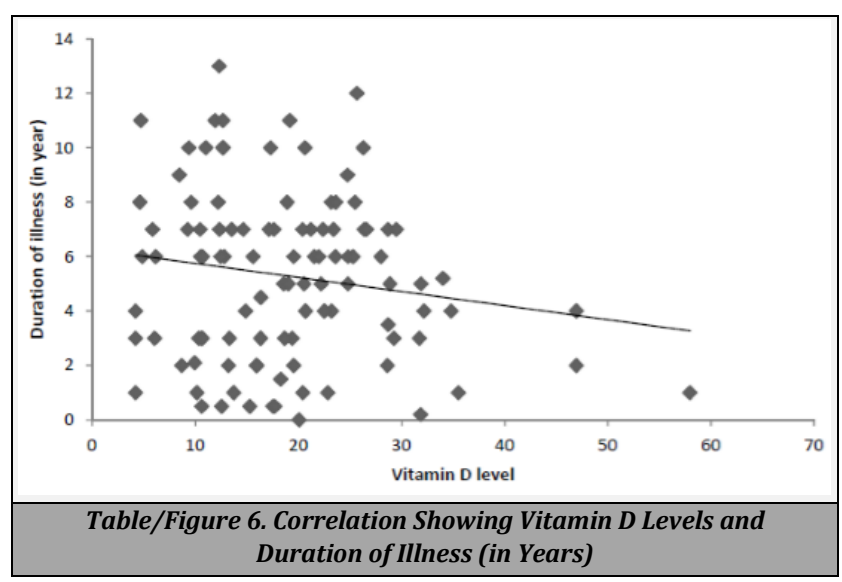

There was a statistically insignificant negative correlation between vitamin $\mathrm{D}$ level and duration of illness (P-value $=0.107$ ). As the duration of illness increased, there was a decrease in serum vitamin D levels. (Pearson correlation coefficient (r) 0.16) 


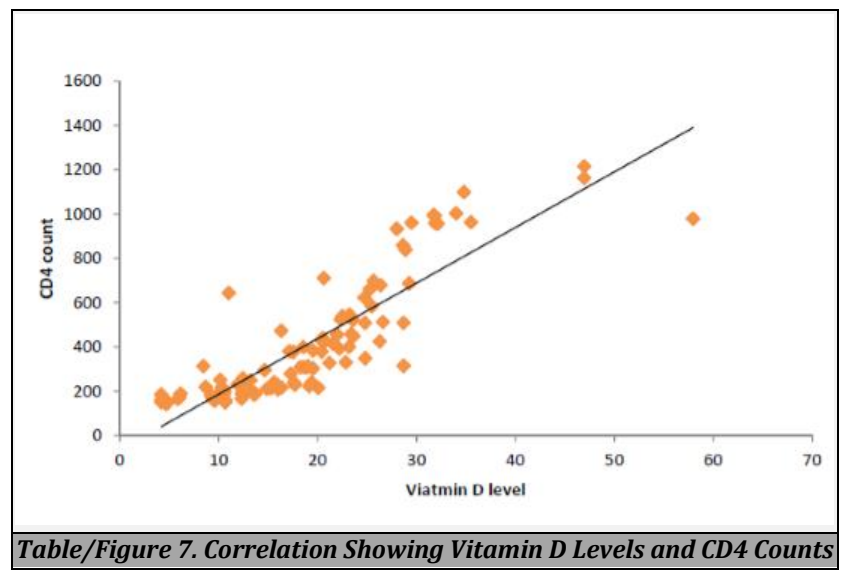

There was a statistically significant positive correlation between vitamin D level and CD4 count ( $\mathrm{P}$-value $<0.001$ ). As the serum vitamin $D$ level increased, there was an increase in CD4 count. (Pearson correlation coefficient (r) 0.87)

The mean $\mathrm{Hb}$ of the participants was observed to be 10.1 $\% \pm 2.4 \mathrm{~g} / \mathrm{dl}$. Among 104 participants, 82 (78.9 \%) patients had anaemia. Mean (SD) $\mathrm{Hb}$ among males and females was 11.04 (2.56) and 9.1(1.74) respectively and found to be statistically significant. There was a statistically significant positive correlation between vitamin $\mathrm{D}$ level and haemoglobin (P-value < 0.001). As the serum vitamin D level increased, there was an increase in haemoglobin level. (Pearson correlation coefficient (r) 0.74)

There was a statistically significant positive correlation (moderately strong) between vitamin D level and total leukocyte count (P-value < 0.001). As the serum vitamin D level increased, there was an increase in leukocyte count. (Pearson correlation coefficient (r) 0.46). The mean (SD) total leukocyte count of our study participants was 6523.2 (1714.3). There was a statistically significant positive correlation (moderately strong) between vitamin D level and mean corpuscular volume (MCV) (P-value $<0.107)$. As the serum vitamin D level increased, there was an increase in MCV value. (Pearson correlation coefficient (r) 0.48). The mean (SD) MCV value of our study group was 88.5 (8.0) $\mathrm{fl} / \mathrm{RBC}$.

The mean (SD) level of vitamin D among patients without HIV/TB co-infection was 21.97 (9.62) $\mathrm{ng} / \mathrm{ml}$ and among patients with HIV/TB co-infection was 11.72 (3.8) ng/ml. There was a statistically significant difference in vitamin $\mathrm{D}$ level between patients with and without HIV/TB co-infection. $(\mathrm{P}<0.001)$.

Among the patients with HIV/TB co-infection, mean(SD) vitamin D levels in patients with Pulmonary Kochs, TB lymphadenopathy, TB pleural effusion, TB meningitis were 11.25 (4.15), 11.96 (4.18), 13.61 (2.21) and 11.63 (1.31) respectively. A statistically significant difference in vitamin $D$ level was seen between different manifestations of TB in study participants.

\section{DISCUSSION}

Many studies have shown that vitamin D inhibits HIV replication by activation of an antimicrobial peptide cathelicidin and induction of autophagy and other mechanisms. In our study, we determined the levels of vitamin D in HIV positive individuals. Of the 104 HIV positive patients, $94(90.4 \%)$ patients had hypovitaminosis D $(<30$ $\mathrm{ng} / \mathrm{ml}$ ) and $10(9.6 \%)$ patients had normal vitamin D levels (> $30 \mathrm{ng} / \mathrm{ml}$ ). Among the 94 patients who had hypovitaminosis D, 34 patients had insufficient (20-29.9 $\mathrm{ng} / \mathrm{ml}$ ) and 60 patients had deficient $(<20 \mathrm{ng} / \mathrm{ml})$ vitamin $\mathrm{D}$ levels.

The Euro SIDA study by Jean-Paul Viarda, et al. found that among the 1985 HIV positive study patients, $89 \%$ had hypovitaminosis $\mathrm{D}(<30 \mathrm{ng} / \mathrm{ml})$ and $11 \%$ had normal vitamin D levels (> $30 \mathrm{ng} / \mathrm{ml}) .{ }^{16}$

An Indian study by Sarita Bajaj et al. done in Allahabad, Uttar Pradesh demonstrated that out of the 45 HIV positive patients, 42 cases (93.3\%) had vitamin D deficiency $(<30$ $\mathrm{ng} / \mathrm{ml}$ ) and normal vitamin D levels $(>30 \mathrm{ng} / \mathrm{l})$ in 3 patients $(6.7 \%) \cdot{ }^{17}$

A study on 112 HIV positive patients by Allison Bearden et al. showed that $73 \%$ of patients had vitamin D deficient levels $<30 \mathrm{ng} / \mathrm{mL}$ and $27 \%$ patients had normal vitamin $\mathrm{D}$ levels(> $30 \mathrm{ng} / \mathrm{ml}) .18$

A study by Mariam Aziz et al. on 204 HIV positive women showed that $89 \%$ had vitamin D levels $<30 \mathrm{ng} / \mathrm{ml}$ and $11 \%$ had normal vitamin D levels.

In another study in Belgium by Anali Conesa-Botella et al. on 89 HIV positive individuals, $81.6 \%$ had vitamin D levels < $30 \mathrm{ng} / \mathrm{ml}$ and $19.4 \%$ had normal vitamin D levels. ${ }^{19}$

Another study on HIV infected Tanzanian women by Sourabh Mehta et al. demonstrated that low vitamin D levels were significantly associated with increased risk of HIV disease progression, $46 \%$ higher risk of developing severe anaemia. Women with high levels of vitamin D had a $42 \%$ lower risk of all-cause mortality compared to women with low levels of vitamin D. There was no significant correlation between vitamin D deficiency, AIDS-related mortality and Tcell counts in that study.

Those with high vitamin D had a significantly lower risk of clinical progression during the subsequent follow-up. It also found a strong association between the low vitamin D levels and the two main endpoints of AIDS and all-cause death events. (90) Another study on HIV-infected Tanzanian women by Sourabh Mehta et al. demonstrated that low vitamin D levels were significantly associated with increased risk of HIV disease progression, with $46 \%$ at higher risk of developing severe anaemia. Women with high levels of vitamin D had a $42 \%$ lower risk of all-cause mortality compared to women with low levels of vitamin D. There was no significant correlation between vitamin D deficiency, AIDS-related mortality and T-cell counts in this study. (85) Study by Sarita Bajaj et al. also showed a positive association between CD4 levels and 25 hydroxyvitamin D (92). From the above observations, vitamin D deficiency represents a novel, independent, poor prognostic marker in HIV infection.

Our study shows the importance of the evaluation of vitamin D levels in HIV positive patients. Vitamin D supplementation in deficiency patients helps to slow the disease progression and improvement in the quality of life. However, furthermore, studies are required to establish the vitamin D role in HIV, as there are fewer data available at present regarding the same. 


\section{CONCLUSIONS}

Vitamin D deficiency is frequently observed in HIV positive patients. Low vitamin D levels are associated with low CD4 counts, vitamin D levels are correlated with the WHO staging of HIV. Patients with low vitamin D levels have more severe diseases. Lower vitamin D levels are associated with more opportunistic infections compared to the patients with higher vitamin D levels. Tuberculosis is the most common opportunistic infection observed in our study. A positive correlation was observed between vitamin D levels, haemoglobin, MCV and total leukocyte count. All the above data are statistically significant i.e., $\mathrm{P}<0.001$. The above data suggest the importance of vitamin $\mathrm{D}$ in HIV positive patients and hence its levels to be checked regularly.

Data sharing statement provided by the authors is available with the full text of this article at jemds.com.

Financial or other competing interests: None.

Disclosure forms provided by the authors are available with the full text of this article at jemds.com.

\section{REFERENCES}

[1] Mehta S, Giovannucci E, Mugusi FM, et al. Vitamin D status of HIV-infected women and its association with HIV disease progression, anemia, and mortality. PLoS One 2010;5(1):e8770.

[2] Smith LH, Waetjen LE, Paik CK, et al. Trends in the safety of inpatient hysterectomy for benign conditions in California, 1991-2004. Obstet Gynecol 2008;112(3):55361.

[3] Lips P. Vitamin D deficiency and secondary hyperparathyroidism in the elderly: consequences for bone loss and fractures and therapeutic implications. Endocr Rev 2001;22(4):477-501.

[4] Martins D, Wolf M, Pan D, Zet al. Prevalence of cardiovascular risk factors and the serum levels of 25hydroxyvitamin D inthe United States. Arch Intern Med 2007;167(11):1159-65.

[5] Holick MF. Vitamin D deficiency. N Engl J Med 2012;357(3):266-81.

[6] Campbell GR, Spector SA. Vitamin D inhibits human immunodeficiency virus type 1 and Mycobacterium tuberculosis infection in macrophages through the induction of autophagy. PLoS Pathog 2012;8(5):e1002689.

[7] Campbell G SS. Vitamin D3 triggers autophagy in human macrophages thatinhibits productive HIV-1/TB coinfection. In: 18th Conference on Retrovirusesand
Opportunistic Infections Boston, MA 2011 February 27March 2, 2011.

[8] Dietary reference intakes for calcium, magnesium, phosphorus, vitamin D, and fluoride. Standing Committee on the Scientific Evaluation of Dietary Reference Intakes.Washington (DC): National Academies Press (US); 1997:190-249.

[9] Cozzolino M, Vidal M, Arcidiacono MV, et al. HIVprotease inhibitors impair vitamin $\mathrm{D}$ bioactivation to 1,25-dihydroxyvitamin D. AIDS 2003;17(4):513-20.

[10] Brown TT, McComsey GA. Association between initiation of antiretroviral therapy with efavirenz and decreases in 25-hydroxyvitamin D. Antivir Ther 2010;15(3):425-9.

[11] Gyllensten K, Josephson F, Lidman K, et al. Severe vitamin $\mathrm{D}$ deficiency diagnosed after introduction of antiretroviral therapy including efavirenz in a patient living at latitude 59 degrees N. AIDS 2006;20(14):19067.

[12] Hariparsad N, Nallani SC, Sane RS, et al. Induction of CYP3A4 by efavirenz in primary human hepatocytes: comparison with rifampin and phenobarbital. J Clin Pharmacol 2004;44(11):1273-81.

[13] Teichmann J, Stephan E Lange U, et al. Osteopenia in HIVinfected women prior to highly active antiretroviral therapy. J Infect 2003;46(4):221-7.

[14] Haug C, Müller F, Aukrust P, et al. Subnormal serum concentration of 1,25-vitamin $\mathrm{D}$ in human immunodeficiency virus infection: correlation with degree of immune deficiency and survival. J Infect Dis 1994;169(4):889-93.

[15] Haug CJ, Aukrust P, Haug E, et al. Severe deficiency of 1,25-dihydroxyvitamin D3 in human immunodeficiency virus infection: association with immunological hyperactivity and only minor changes in calcium homeostasis. J Clin Endocrinol Metab 2015;83(11):38328.

[16] Viard JP, Souberbielle JC, Kirk O, et al. Vitamin D and clinical disease progression in HIV infection: results from the EuroSIDA study. AIDS 2011;25(10):1305-15.

[17] Bajaj S, Bharghav A, Gupta SK, et al. Association of vitamin D levels, lipid profile and intima media thickness in HIV positive patients. Indian J Endocrinol Metab 2012;16(Suppl 2):S411-2.

[18] Bearden A, Abad C, Gangnon R, et al. Cross-sectional study of vitamin D levels, immunologic and virologic outcomes in HIV-infected adults. J Clin Endocrinol Metab 2013;98(4):1726-33.

[19] Conesa-Botella A, Florence E, Lynen L, et al. Decrease of vitamin D concentration in patients with HIV infection on a non nucleoside reverse transcriptase inhibitor containing regimen. AIDS Res Ther 2010;7:40. 